\title{
Pembuatan Media Belajar Sains Sederhana bagi Guru Sekolah Dasar di Kota Tarakan
}

\author{
Kartini*, Kadek Dewi Wahyuni Andari, Mety Toding Bua, Agustinus Toding Bua, Ary Felipur \\ Satya, Rasmawati, Nasruddin, Ariansyah \\ Jurusan Pendidikan Guru Sekolah Dasar, Fakultas Keguruan dan Ilmu Pendidikan, \\ Universitas Borneo Tarakan \\ *Coresponding Author: kartinipgsd@ borneo.ac.id \\ Dikirim: 18-10-2021; Direvisi: 29-10-2021; Diterima: 01-11-2021
}

\begin{abstract}
Abstrak: Kegiatan pengabdian kepada masyarakat ini dirancang melalui kegiatan pendampingan pembuatan media belajar sains sederhana. Kegiatan ini bertujuan untuk membantu guru-guru di Sekolah Dasar khususnya guru-guru di SDN 037 Tarakan yang meliputi a) menambah pengetahuan guru SD/MI dalam merancang pembelajaran IPA, dan b) melatih keterampilan guru dalam membuat dan menggunakan media belajar sains sederhana. Ketercapaian target yang dicapai memberikan pengetahuan kepada guru-guru tentang cara mendesain media dan membuat media belajar sains sederhana sangat terampil. Kegiatan pendampingan ini berhasil membuat media belajar sains sederhana bersama guru-guru di SDN 037 Tarakan yang terdiri dari 3 media, diantaranya 1) media belajar sains sederhana berupa media big book, 2) media belajar sains sederhana berupa media kartu truth and dare, dan 3) media belajar sains sederhana berupa media permainan ular tangga.Guru-guru sangat mengharapkan kegiatan ini berlangsung lebih lama, sehingga dapat lebih banyak lagi media yang dibuat untuk membantu proses pembelajaran. Pendampingan diharapkan dapat dilakukan secara rutin ke sekolah sebagai bahan untuk bertukar pengetahuan bersama mahasiswa dan dosen yang ada di Universitas Borneo Tarakan. Selain itu, guru-guru di SDN 037 Tarakan sangat antusias dan merespon baik kegiatan ini yangmana memberikan pengetahuan dan keterampilan tambahan untuk dimanfaatkan disaat proses pembelajaran berlangsung.
\end{abstract}

Kata kunci: media belajar sains sederhana; big book; truth and dare; permainan ular tangga

\begin{abstract}
This community service activity was designed through mentoring activities for making simple science learning media. This activity aims to help teachers in elementary school, especially teachers at SDN 037 Tarakan, which includes a) increasing the knowledge of SD / MI teachers in designing science learning, and b) training teacher's skills in making and using simple science learning media. The attainment of the target achieved provides knowledge to teachers on how to design media and make simple very skilled science learning media. This mentoring activity succeeded in making simple science learning media with teachers at SDN 037 Tarakan consisting of 3 media, including 1) simple science learning media in the form of big book media, 2) simple science learning media in the form of truth and dare card media, and 3) a simple science learning media in the form of a game of snakes and ladders. The teachers really expect this activity to last longer, so that more media can be created to help the learning process. Assistance was expected to be carried out regularly to schools as a material to exchange knowledge with students and lecturers at the University of Borneo Tarakan. In addition, the teachers at SDN 037 Tarakan were very enthusiastic and responded well to this activity which provided additional knowledge and skills to be used during the learning process.
\end{abstract}

Keywords: simple science learning media; big book; truth and dare; and snake ladder games

@2021 Bima Abdi (https://jurnal.bimaberilmu.com/index.php/ba-jpm) 


\section{PENDAHULUAN}

Pendidikan merupakan usaha sadar dan terencana untuk mewujudkan suasana belajar dan proses pembelajaran agar peserta didik secara aktif mengembangkan potensi dirinya untuk memiliki kekuatan spiritual, keagamaan, pengendalian diri, kepribadian, kecerdasan, akhlak mulia, serta keterampilan yang diperlukan dirinya, masyarakat, bangsa dan negara. Pendidikan di Indonesia bertujuan untuk mempersiapkan manusia Indonesia yang memiliki kemampuan hidup sebagai pribadi dan warga Negara yang beriman, produktif, kreatif, inovatif, dan afektif serta mampu berkontribusi pada kehidupan bermasyarakat, berbangsa, dan bernegara. Melalui proses Pendidikan dan pembelajaran akan terbentuk sumber daya manusia yang berkualitas. Tenaga pendidik dalam hal ini Guru, merupakan ujung tombak dalam melaksanakan pendidikan dan berpengaruh pada proses pembelajaran. Kemampuan seorang guru dalam melaksanakan proses pembelajaran dapat dilihat dari kepiawaian guru mengelola proses pembelajaran, salah satu kemampuan guru yang dimiliki adalah kemampuan mengelola pembelajaran IPA di sekolah dasar.

Pembelajaran IPA identik dengan fenomena yang ada dalam kehidupan seharihari sehingga pembelajaran dapat didesain menggunakan model penemuan melalui kegiatan observasi atau eksperimen. Hal ini akan membantu dalam mencapai tujuan pembelajaran dan penggunaan media belajar akan membantu siswa dalam memahami suatu materi atau konsep. Penggunaan media pembelajaran di dalam kelas memberikan manfaat yang lebih bagi siswa. Hal ini ditunjukkan dari beberapa hasil penelitian terkait dengan penggunaan media pembelajaran antara lain (Putra \& Sujarwanto, 2017), (Prihatiningtyas \& Putra, 2018), dan (Mardhiah \& Akbar, 2018). Penerapan media belajar dapat meningkatkan penguasaan konsep (Putra and Sujarwanto, 2016) dan hasil belajar siswa (Syafrina, Farhan, \& Ropisa, 2016). Selain itu, media belajar dapat menumbuhkan antusiasme peserta didik dalam mengikuti proses pembelajaran (Mardhiah \& Akbar, 2018). (Prihatiningtyas \& Putra, 2018) menambahkan bahwa penggunaan media belajar di dalam kelas dapat meningkatkan keterampilan dan mengembangkan psikomotorik peserta didik.

Kegiatan pengabdian kepada masyarakat ini dirancang melalui kegiatan pendampingan pembuatan media belajar sains sederhana. Kegiatan ini bertujuan untuk membantu guru-guru di Sekolah Dasar khususnya guru-guru di SDN 037 Tarakan yang meliputi a) menambah pengetahuan guru SD/MI dalam merancang pembelajaran IPA, dan b) melatih keterampilan guru dalam membuat dan menggunakan media belajar sains sederhana.

\section{METODE PELAKSANAAN KEGIATAN}

Kegiatan pengabdian kepada masyarakat $(\mathrm{PkM})$ dilaksanakan melalui kegiatan pendampingan kepada guru-guru di SDN 037 Tarakan. Pendampingan pembuatan media sains sederhana diharapkan dapat diaplikasikan di dalam kelas. Metode pelaksanaan yang digunakan yaitu kegiatan ceramah, diskusi, dan praktek penggunaan media belajar sains sederhana. Proses pelaksanaan kegiatan PkM pembuatan media belajar sains sederhana melalui beberapa tahap, yaitu 1) tahap persiapan, 2) tahap pelaksanaan, dan 3) tahap akhir.

Tahap persiapan dilakukan selama 1 minggu. Apapun secara rinci kegiatan yang dilakukan antara lain: 1) Komunikasi via whatsapp dengan kepala sekolah SDN 037 Tarakan terkait pelaksanaan kegiatan, peserta (guru-guru) yang terlibat, dan pembahasan media belajar sains yang akan didesain, 2) Mempersiapkan mahasiswa 
yang membantu untuk proses persiapan bahan-bahan, mendesain media belajar sains sederhana, dan perakitan serta finishing media yang digunakan. Tahap pelaksanaan kegiatan pendampingan pembuatan media belajar sains sederhana dilakukan di SDN 037 Tarakan. Tahap ini menggunakan metode ceramah, diskusi, dan praktek membuat media belajar sains sederhana dengan bantuan tim PkM yang terdiri dari ketua tim, dosen pendamping (Kadek Dewi Wahyuni Andari, M.Pd, dan Mety Toding Bua, M.Pd), dan mahasiswa. Tahap akhir kegiatan pendampingan pembuatan media belajar sains sederhana dilakukan dengan menyusun laporan akhir kegiatan bersama tim PkM.

\section{IMPELMENTASI KEGIATAN DAN PEMBAHASAN}

Kegiatan pengabdian kepada masyarakat ini dirancang melalui kegiatan pendampingan pembuatan media belajar sains sederhana. Kegiatan ini bertujuan untuk membantu guru-guru di Sekolah Dasar khususnya guru-guru di SDN 037 Tarakan yang meliputi a) menambah pengetahuan guru SD/MI dalam merancang pembelajaran IPA, dan b) melatih keterampilan guru dalam membuat dan menggunakan media belajar sains sederhana. Untuk mencapai kegiatan pendampingan pembuatan media belajar sains sederhana, diperlukan 3 (tiga) tahapan yang dilakukan. Proses pelaksanaan kegiatan PkM pembuatan media belajar sains sederhana melalui beberapa tahap, yaitu 1) tahap persiapan, 2) tahap pelaksanaan, dan 3) tahap akhir.

Tahap persiapan dilakukan selama 1 minggu. Apapun secara rinci kegiatan yang dilakukan antara lain: 1) Komunikasi via whatsapp dengan kepala sekolah SDN 037 Tarakan terkait pelaksanaan kegiatan, peserta (guru-guru) yang terlibat, dan pembahasan media belajar sains yang akan didesain, 2) Mempersiapkan mahasiswa yang membantu untuk proses persiapan bahan-bahan, mendesain media belajar sains sederhana, dan perakitan serta finishing media yang digunakan. Terget pada tahap persiapan berhasil mempersiapkan 3 media belajar sains sederhana yaitu 1) media big book, 2) media kartu truth and dare, dan 3) media permainan ular tangga.

Tahap pelaksanaan kegiatan pendampingan pembuatan media belajar sains sederhana dilakukan di SDN 037 Tarakan. Tahap ini menggunakan metode ceramah, diskusi, dan praktek membuat media belajar sains sederhana dengan bantuan tim PkM yang terdiri dari ketua tim, dosen pendamping (Kadek Dewi Wahyuni Andari, M.Pd, dan Mety Toding Bua, M.Pd), dan mahasiswa PGSD. Pada tahapan ini, guru-guru dikelompokkan menjadi 3 kelompok yang jumlahnya 3 orang guru di tiap kelompok. Kelompok 1 membuat media belajar sains sederhana berupa big book. Media big book dibuat oleh guru-guru dengan menggunakan kertas gambar, pensil, pensil warna, spidol, dan menyusun materi pertumbuhan dan perkembangbiakan pada makhluk hidup untuk dituliskan pada media big book. Kelompok 2 membuat media belajar sains sederhana berupa media kartu truth and dare. Media kartu Truth and dare ini berisi pertanyaan dan jawaban pada masingmasing kartu. Pertanyaan dan jawaban yang dipersiapkan berkaitan dengan materi IPA. Kelompok 3 membuat media belajar sains sederhana berupa media permainan ular tangga. Media permainan ular tangga ini memiliki desain dengan materi tematik dengan konsep belajar sambal bermain.

Guru-guru ditiap kelompok didampingi oleh mahasiswa dan dosen yang membantu mengarahkan dan membuat media yang telah dipersiapkan. Pembuatan media belajar sains sederhana berupa media big book didampingi oleh Ibu Kadek Dewi Wahyuni Andari, M.Pd dan mahasiswa Ary Felipur Satya. Kemudian 
pembuatan media belajar sains sederhana berupa media kartu truth and dare didampingi oleh Ibu Kartini, S.Pd., M.Sc dan mahasiswa Nasrudin. Terakhir pembuatan media belajar sains sederhana berupa media permainan ular tangga didampingi oleh Ibu Mety Toding Bua, M.Pd dan mahasiswa Rismawati.

Kegiatan pendampingan pembuatan media belajar sains sederhana di SDN 037 Tarakan dapat terlaksana dengan baik dan sesuai dengan target yang diharapkan. Target yang diharapkan ini dapat tercapai dengan hasil antara lain 1) guru-guru dapat mendesain media belajar sains sederhana pada materi pelajaran yang biasa dilakukan dikelas, 2) guru-guru dapat membuat media belajar sains sederhana dengan baik dan antusias. Respon guru-guru yang ikut dalam kegiatan pendampingan pembuatan media belajar sains sederhana memberikan masukan untuk tim PkM kembangkan kedepannya. Masukan ini agar pendampingan dapat dilakukan secara rutin ke sekolah sebagai bahan untuk bertukar pengetahuan bersama mahasiswa dan dosen yang ada di Universitas Borneo Tarakan. Selain itu, guru-guru di SDN 037 Tarakan sangat antusias dan merespon baik kegiatan ini yangmana memberikan pengetahuan dan keterampilan tambahan untuk dimanfaatkan disaat proses pembelajaran berlangsung. Guru-guru sangat mengharapkan kegiatan ini berlangsung lebih lama, sehingga dapat lebih banyak lagi media yang dibuat untuk membantu proses pembelajaran. Media belajar sains sederhana yang telah dibuat disajikan pada Gambar 1, 2, dan 3 berikut.

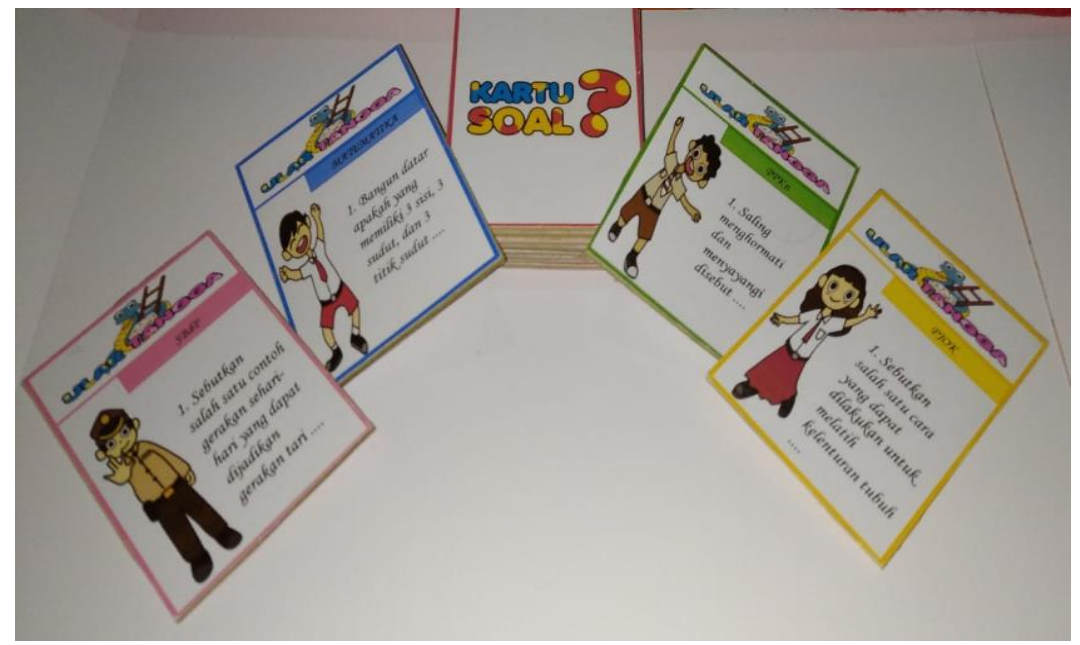

(a) Kartu Ular Tangga

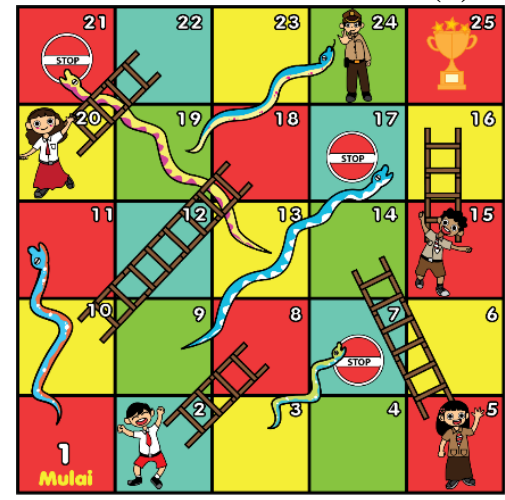

(b) Papan Ular Tangga

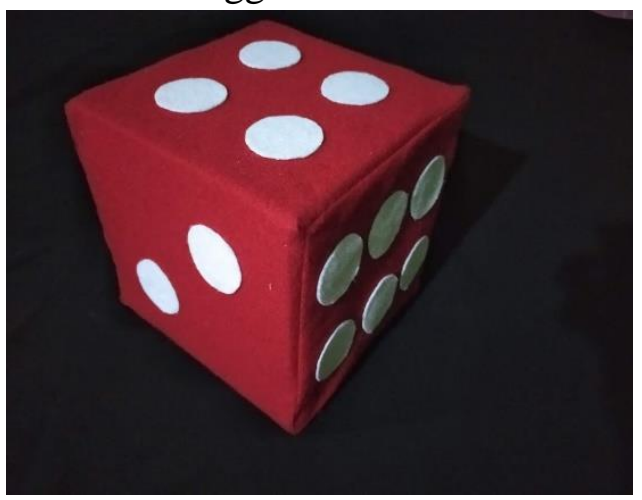

(c) Dadu Permainan

Gambar 1. Media Belajar Sains Sederhana Berupa Permainan Ular Tangga

@ 2021 Bima Abdi (https://jurnal.bimaberilmu.com/index.php/ba-jpm) 

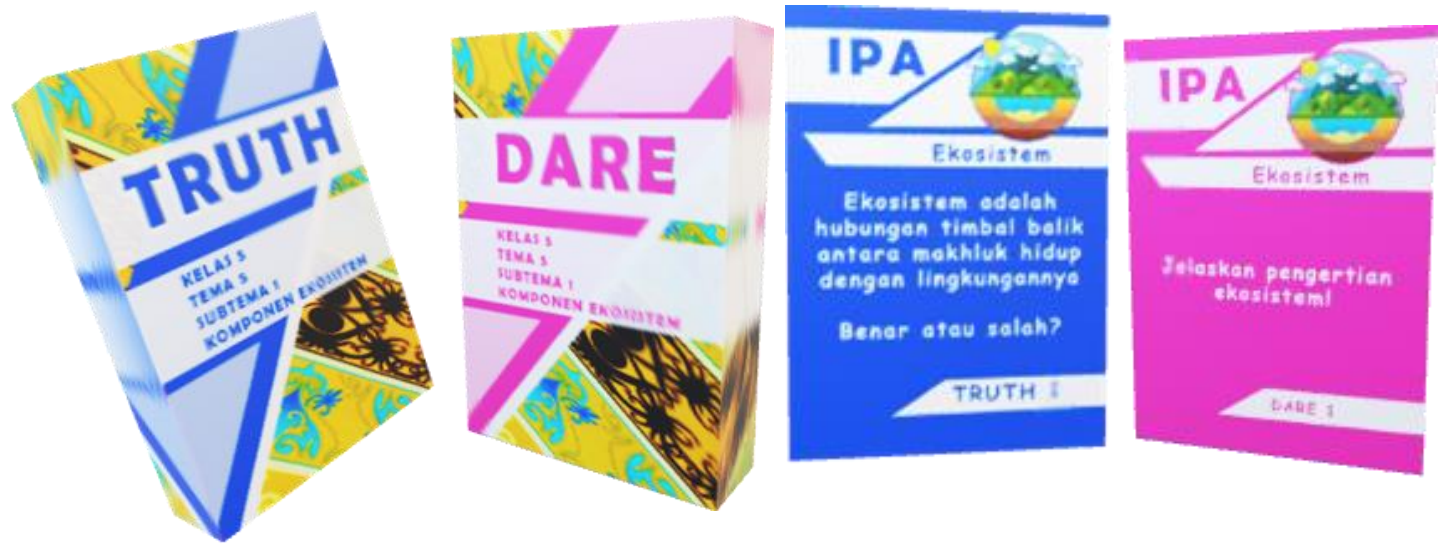

Gambar 2. Media Belajar Sains Sederhana Berupa Kartu Truth and dare
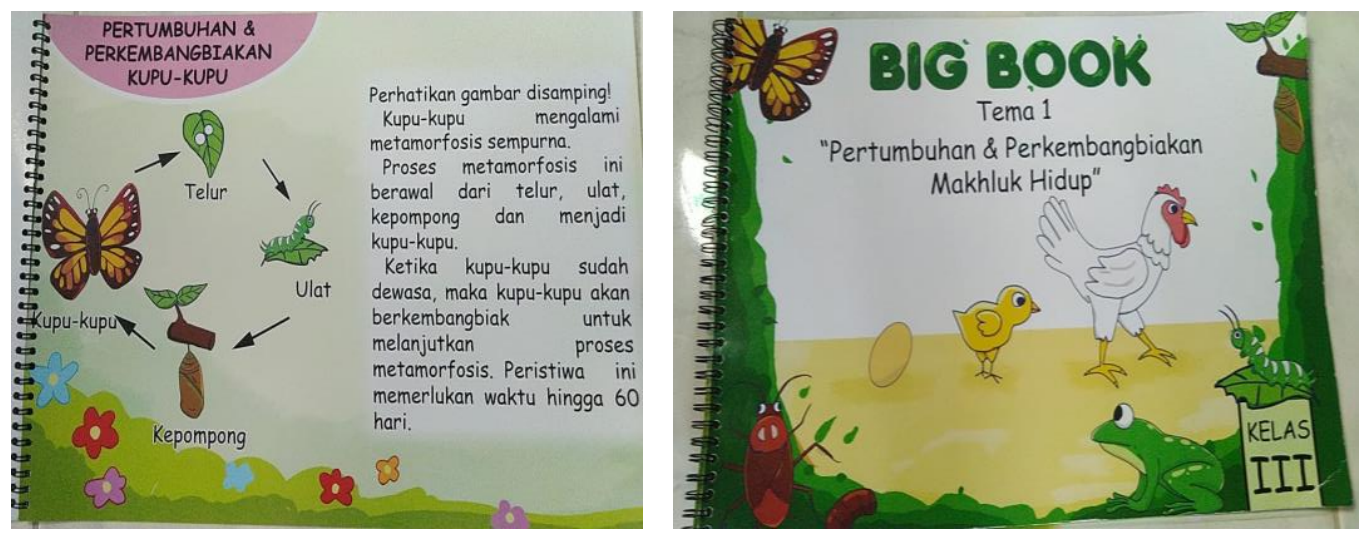

Gambar 3. Media Belajar Sains Sederhana Berupa Big book

\section{SIMPULAN}

Kegiatan pengabdian kepada masyarakat yang telah dilaksanakaan melalui kegiatan pendampingan pembuatan media belajar sains sederhana di SDN 037 Tarakan menunjukkan bahwa guru cukup baik dan terampil dalam membuat media belajar sains sederhana. Ketercapaian target yang dicapai memberikan pengetahuan kepada guruguru tentang cara mendesain media dan membuat media belajar sains sederhana sangat terampil. Kegiatan pendampingan ini berhasil membuat media belajar sains sederhana bersama guru-guru di SDN 037 Tarakan yang terdiri dari 3 media, diantaranya 1) media belajar sains sederhana berupa media big book, 2) media belajar sains sederhana berupa media kartu truth and dare, dan 3) media belajar sains sederhana berupa media permainan ular tangga.

Guru-guru sangat mengharapkan kegiatan ini berlangsung lebih lama, sehingga dapat lebih banyak lagi media yang dibuat untuk membantu proses pembelajaran. Pendampingan diharapkan dapat dilakukan secara rutin ke sekolah sebagai bahan untuk bertukar pengetahuan bersama mahasiswa dan dosen yang ada di Universitas Borneo Tarakan. Selain itu, guru-guru di SDN 037 Tarakan sangat antusias dan merespon baik kegiatan ini yang mana memberikan pengetahuan dan keterampilan tambahan untuk dimanfaatkan disaat proses pembelajaran berlangsung. 


\section{UCAPAN TERIMA KASIH}

Dalam kesempatan ini perkenankan kami menyampaikan ucapan terima kasih Kepada Universitas Borneo Tarakan yang memberikan dana penelitian DIPA, sehingga terselesaikan kegiatan ini dengan baik, dan untuk tema-teman Dosen yang terlibat, terimakasih atas kerjasamanya serta guru-guru di SDN 037 atas semangatnya yang luar biasa dalam mengikuti kegiatan hingga selesai dan adik-adik mahasiswa yang membantu dalam pendampingan dan bertukar informasi.

\section{DAFTAR PUSTAKA}

Anggoro, Subuh, Sri Harmianto, and Pratik Dwi Yuwono. (2018). Upaya Meningkatkan Kemampuan Pedagogik Guru Melalui Pelatihan Pembelajaran Tematik Sains Menggunakan Inquiry Learning Process Dan Science Activity Based Daily Life. Jurnal Pengabdian Dan Pemberdayaan Masyarakat.

Mardhiah, A., \& Akbar, S. A. (2018). Efektivitas media pembelajaran terhadap hasil belajar kimia siswa SMA Negeri 16 Banda Aceh. Lantanida Journal, 6(1), 4958 .

Prihatiningtyas, S., \& Putra, I. A. (2018). Efektivitas penggunaan alat peraga sederhana berbasis pendekatan sains teknologi masyarakat pada materi fluida statis. Jurnal Riset dan Kajian Pendidikan Fisika, 5(2), 102-107.

Putra, Ino Angga and Eko Sujarwanto. (2016). Bahan Ajar Alat Ukur Dan Pengukuran Fisika Berbasis Inkuiri Terbimbing. Jurnal Pendidikan Sains.

Putra, Ino Angga and Eko Sujarwanto. (2017). Rekonstruksi Bahan Ajar Multimedia Interaktif Pada Mata Kuliah Alat Ukur Dan Pengukuran Dengan Pendekatan Behavioristik Terhadap Penguasaan Konsep Peserta Didik. Prosiding Seminar Nasional Pendidikan IPA 2:196-205.

Suprapti, Endang, Sujinah Sujinah, Wiwi Wikanta, and Suher Suher. (2016). Penguatan Kemampuan Guru Dalam Mengembangkan Perangkat Pembelajaran Tematik Berbasis Student Centre Learning (SCL) Di SDN Petemon IX Surabaya. AKSIOLOGIYA : Jurnal Pengabdian Kepada Masyarakat.

Syafrina, Alfiati, Ahmad Farhan, \& Ropisa. (2016). Efektifitas Media Animasi Dalam Pencapaian Nilai Kriteria Ketuntasan Minimal. Jurnal Pesona Dasar 2(4):1-7. 